\title{
Erratum to: Unenhanced Cone Beam Computed Tomography and Fusion Imaging in Direct Percutaneous Sac Injection for Treatment of Type II Endoleak: Technical Note
}

Gianpaolo Carrafiello ${ }^{1}$ - Anna Maria Ierardi ${ }^{1}$ - Alessandro Radaelli ${ }^{2}$.

${\text { Giuseppe De } \text { Marchi }^{1} \text { - } \text { Chiara Floridi }^{1} \text { - Gabriele Piffaretti }}^{3}$ - Federico Fontana ${ }^{1}$

Published online: 9 November 2015

(C) Springer Science+Business Media New York and the Cardiovascular and Interventional Radiological Society of Europe (CIRSE) 2015

\section{Erratum to: Cardiovasc Intervent Radiol}

DOI: $10.1007 / \mathrm{s} 00270-015-1217-x$

The name of one of the authors mistakenly appeared as "Fontana Federico" in the published article. This author's correct given name is Federico and his correct family name is Fontana.

The online version of the original article can be found under doi:10. 1007/s00270-015-1217-x.

\section{Gianpaolo Carrafiello}

gcarraf@gmail.com

1 Interventional Radiology, Department of Radiology, Insubria University, Viale Borri, 57, 21100 Varese, VA, Italy

2 Philips Healthcare, Best, The Netherlands

3 Vascular Surgery Department, University of Insubria, Viale Borri, 57, 21100 Varese, VA, Italy 